\title{
Management of COVID-19 Crisis in Guilan Province in Northern Iran
}

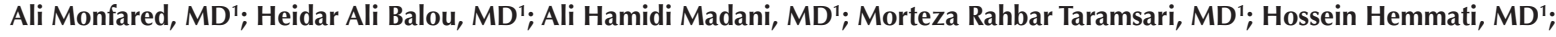

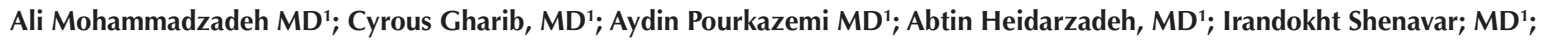 \\ Leila Akhoundzadeh, MD $^{1 *}$
}

'Razi Hospital, School of Medicine, Guilan University of Medical Sciences, Rasht, Iran

\section{Dear Editor,}

COVID-19, caused by SARS-CoV-2 virus, is undoubtedly a major crisis of unparalleled magnitude for the humankind and has affected almost all-human societies. ${ }^{1}$ As such; its management requires emergent decisions and actions. Iran is no exception and has been dealing with the challenges of COVID-19 since it officially became epidemic in the country in late February.

Since in the recent years, our country and most parts of the world have not been experienced a similar crisis and as Guilan was faced with the global crisis much sooner than many other provinces of Iran and other countries, we are sharing our experience with other coronavirus centers and writing this report on behalf of all physicians, assistants and nurses involved in the coronavirus crisis in Rasht, Guilan University of Medical Sciences.

Rasht is a Guilan plain on the Caspian coast in northern Iran, and its population is about nine hundred thousand. ${ }^{2}$

From the beginning of the crisis in Rasht (February 20, 2020) until March 30, 2020, we admitted 4023 patients with acute respiratory syndromes to Rasht coronavirus centers.

Out of 4023 patients, polymerase chain reaction (PCR) tests were performed for only 1016 cases, of whom only 661 had a positive coronavirus result. For many of the patients, the test was not performed because of the limitations and lack of kits.

Our overall goal was to optimize the activities against the COVID-19 crisis and minimize the resulting damages. In this regard, after the establishment of the Crisis Committee and regular and frequent meetings of "Thinking Rooms" and applying Thought Thinking Method, the dimensions of the crisis were examined. Based on the discussions, we adjusted our operational plan in the field of Treatment, Health and Protection relying on human resources and the available facilities.

Our treatment plan included a combination of a flowchart (the prescriptions of three or four medications including hydroxychloroquine, Tamiflu, kaletra and ribavirin) and the choice of physicians depending on the patient's condition.

Daily changes were made to the program by obtaining accurate and detailed field reports. The Crisis Committee members were responsible for managing coronavirus hospitals, coordinating the faculty members and medical residents and interns, supplying procurement and equipment, and providing statistics and field information.

The measures that were gradually operationalized were as follows.

\section{In the Field of Treatment}

A. All the personnel working at the center and volunteer personnel were trained by the Hospital Infection Control team and Environmental Health Experts to fully comply with the principles of personal protection.

B. A flowchart was developed for managing acute respiratory illness and banner-sized copies were installed in triage stations and emergency rooms to facilitate and accelerate decision making by physicians; the triage physician were trained accordingly.

C. The design of emergency rooms in hospitals was changed to improve the patients congestion management in the waiting rooms to comply with social distancing principles and minimize disease transmission.

D. Taking and recording medical history from patients suspected of COVID-19 were modified based on the most recent literature.

E. Routine instruction sheets were developed for the patients with COVID-19 and it was made possible to select the instructions according to the patients) condition.

F. A 6- to 12-hour short stay unit was devised as an intermediate ward for patients to be monitored and evaluated at least 3 times a day by an infectious disease specialist or an internist, for making decision for admission or discharge. 
G. All the internal medicine physicians in different subspecialty fields were engaged due to the limited number of infectious disease specialists and pulmonologists. Also, all the senior internal medicine assistants were engaged for managing the departments. Assistants in other specialties and internship students (voluntarily) were allocated to the afternoon and night shifts.

H. Considering the fact that some infectious disease physicians and internal medicine physicians were infected by the virus, and there was the possibility of other physicians to be infected in case of daily and continuous exposure to the virus, the number of days of exposure was reduced by cooperation of specialists in other fields and assistants after an initial training about the disease.

I. Due to the limitations of hospital beds, a committee of experts was formed to visit patients and discharge the hospitalized patients in the evening shifts, if possible.

J. For hospitalization, the hospital was initially divided into two sections, one building for infectious isolation and the other for non-coronavirus patients. Separate entrances were arranged to stop rapid distribution of the virus. At the same time, another hospital was evacuated and was prepared for admitting nonCOVID-19 cases.

K. After transferring non-COVID-19 cases to the mentioned hospital, the Razi Hospital (first center) was declared as quarantined.

L. The Social Security Hospital (Tamin-E-Ejtemaii) was nominated as the second center for admission of COVID-19 cases; after admission to its full capacity, the Naval Army Hospital (Nirooy-E-Daryaii) and also another training center were assigned for admission of coronavirus cases. After negotiating with private hospitals, a large capacity of the hospitals was allocated to COVID-19 cases.

M. Considering the speedy spread of the coronavirus and lack of beds, the Islamic Revolutionary Guard Corps (IRGC) were committed to prepare an 80-bed field hospital.

N. Given the importance of adequate oxygenation, many volunteers helped financially for purchase of respiratory support devices.

O. The number of oxygen generators in hospitals was also increased to provide the high oxygen demand.

P. A new ICU ward with a capacity of 30 beds was established and became operational in only twenty days.

Q. Due to the lack of personal protective equipment, coordination was made with the Sewing Department. The hospital prepared isolation gowns and protective clothing of the whole body with the same standards as the original clothing.

R. Due to the large number of deaths and the limitation in hospital morgues, arrangements were made to increase the capacity of hospital morgues.

\section{In the Field of Public Health}

A. Following the closure of many outpatient centers, an arrangement was made with certain health centers throughout the city with diagnostic facilities such as pulse oximeters and digital thermometers for visiting patients. So, admission to quarantine centers was reduced significantly, as only suspected subjects were referred there. In this regard, extensive information was provided by the local TV network to inform the citizens.

B. A coronavirus call center was launched and provided all related information to the people.

C. To reduce the number of patients traveling through the city, pharmacies were provided with the necessary medicines in the vicinity of the health centers. The patients were also provided with medication packages at the time of discharge to complete the course of treatment at home.

D. The discharged patients were scheduled to be followed up according to the proposed algorithm of treatment by a hospital-based health expert at the health center closest to the patientss location.

E. Educational pamphlets about continuing treatment and isolation at home were provided to all the patients at the time of discharge.

F. The health system was commanded to detect the active cases in the community.

\section{In the Field of Public Protection}

A. Unnecessary traffic in the hospital was reduced with the help of hospital security guard and the police force.

B. After training, volunteer forces from the IRGC were recruited to serve in the inpatient departments to ensure adequate care for the patients.

C. A few companions were also trained to take care of their patients using personal protective equipment.

\section{Other Capacities}

A. The influence of reputable individuals was very significant in attracting financial assistance, personal protective equipment, and equipping the hospital wards, indicating that altruism still exists extensively in our society.

B. Via the local media, level of public awareness was raised by broadcasting educational programs including participation of physicians in educational programs.

C. The ability of the Judiciary to carry out its functions in solving problems in this period expedited the 
implementation of certain matters.

D. By applying the capacity of the Provincial Government, we utilized the cooperation of all available capacities in the province, as well as attracting assistance from other provinces.

In conclusion, through public participation, benefiting from collective wisdom in achieving practical and scientific solutions in utilizing all internal and external organizational capacities in the field of health care, providing human resources and equipment, we can effectively alleviate the suffering and burden in similar crises.

\section{Authors' Contribution}

All authors contributed equally to this work and they approved the final version of the manuscript for publication.

\section{Conflict of Interest Disclosures}

The authors declare that there are no conflict of interests.

\section{Ethical Statement}

Not applicable

\section{Acknowledgment}

This work would not have been possible without the uninterrupted and continuous effort of all physicians, assistants and nurses involved in the coronavirus crisis in Rasht, Guilan University of Medical Sciences. Words cannot express our gratitude and appreciation to all of them. A Special thanks goes to the following people for helping and managing this crisis (in alphabetical order): Ali Alavi, Zahra Abbasi Ranjbar, Dorrin Aghajani, Amineh Hojjati, Alireza Jafari Nejad, Sahereh Mortazavi, Fatemeh Nejatifar, Siamak Rimaz, Mehdi Shadnoush, Azita Tangestani Nejad.

\section{References}

1. Rothan HA, Byrareddy SN. The epidemiology and pathogenesis of coronavirus disease (COVID-19) outbreak. J Autoimmun. 2020;109:102433. doi: 10.1016/j.jaut.2020.102433.

2. Pourzakarya M, Bahramjerdi SFN. Towards developing a cultural and creative quarter: Culture-led regeneration of the historical district of Rasht Great Bazaar, Iran. Land Use Policy. 2019;89:104218. doi:10.1016/j.landusepol.2019.104218.

Received: March 30, 2020, Accepted: April 12, 2020, ePublished: July 1, 2020

Cite this article as: Monfared A, Balou HA, Hamidi Madani A, Rahbar Taramsari M, Hemmati H, Mohammadzadeh A, et al. Management of COVID-19 crisis in Guilan province in Northern Iran. Arch Iran Med. 2020;23(7):511-513. doi: 10.34172/aim.2020.52.

(c) (1) (C) 2020 The Author(s). This is an open-access article distributed under the terms of the Creative Commons Attribution License (http://creativecommons. org/licenses/by/4.0), which permits unrestricted use, distribution, and reproduction in any medium, provided the original work is properly cited. 